\title{
BMJ Open Needlestick prevention devices: data from hospital surveillance in Piedmont, Italy-comprehensive analysis on needlestick injuries between healthcare workers after the introduction of safety devices
}

\author{
Maria Chiara Ottino (1) , ${ }^{1}$ Andrea Argentero, ${ }^{1}$ Pier Angelo Argentero, ${ }^{2}$ \\ Giacomo Garzaro, ${ }^{1}$ Carla Maria Zotti ${ }^{1}$
}

To cite: Ottino MC, Argentero A, Argentero PA, et al. Needlestick prevention devices: data from hospital surveillance in Piedmont, Italy—comprehensive analysis on needlestick injuries between healthcare workers after the introduction of safety devices. BMJ Open 2019;9:e030576. doi:10.1136/ bmjopen-2019-030576

- Prepublication history for this paper is available online. To view these files please visit the journal online (http://dx.doi. org/10.1136/bmjopen-2019030576).

Received 28 March 2019 Revised 18 September 2019 Accepted 26 September 2019

Check for updates

(c) Author(s) (or their employer(s)) 2019. Re-use permitted under CC BY-NC. No commercial re-use. See rights and permissions. Published by BMJ.

${ }^{1}$ Departement of Public Health and Pediatric Sciences,

Universita degli Studi di Torino, Torino, Italy

${ }^{2}$ Hospital Prevention Infection Unit, Ospedale di Rivoli, Rivoli, Italy

Correspondence to Dr Maria Chiara 0ttino; mottino@unito.it

\section{ABSTRACT}

Objective Needlestick and sharps injuries (NSIs) involving healthcare workers (HCWs) are worldwide under surveillance since long time; the implementation of the European Directive 32/2010 regarding the mandatory use of safety-engineered devices (SEDs) seems to have reduced the number of these accidents. Our surveillance investigated the frequency and the modality of SED-related NSIs in the Piedmont region to verify changes in the epidemiology of these events.

Methods We analysed the exposure records of NSIs, device usage data and structural data of 42 acute care hospitals and compared conventional and safety devices. We calculated the accident rates per 100000 needles and, as a measure of SED efficacy, the relative risk between the use of safety and non-safety devices with a $95 \% \mathrm{Cl}$. We also described the dynamics of the NSIs and the most involved professional groups of HCWs, procedures and devices.

Results Total and specific device accident rates for 100000 needles were lower with the use of SEDs. In 2015-2016, there were 1640 NSIs, with a decreasing absolute number during the observation period; $18 \%$ were SEDs related. Half of the total accidents with SEDs occurred in the patient's room, and nurses were involved in $78 \%$ of the cases. The most involved devices were the butterfly needles and peripheral venous catheters and the most involved procedures were venous sampling (40\%) and phlebotherapy (16\%). The exposures occurred mostly during the procedure, and $45 \%$ of the SED-related injuries occurred during the disposal of the device; $92 \%$ of the SEDs involved had a manual activation mechanism.

Conclusion In agreement with the results of other European studies, our results show that SEDs reduce the risk of percutaneous exposure of HCWs, but in introducing SEDs, we must select those with a higher level of safety (with a passive activation mechanism) and improve the healthcare staff training programmes.
Strengths and limitations of this study

- The study provides device-specific accident rates and relative risk measures and provides a very detailed analysis comparing conventional and safety devices and investigates, case by case, the dynamics, methods, users and devices involved, thus providing a general but detailed picture and a rational explanation for the results found.

- This study offers a model for general interventions and collaborative measures between regional standard surveillance systems and the management of each hospital in the regional network in preventing a common problem. Moreover, by portraying a general framework of the problem, this study provides justification for preventive choices by local management.

- The size of the region included may be a limitation of the study, but the adherence of almost all the hospitals in the region (over 40 structures) to this surveillance network has been tested over the years, and this network provides a solid data source; furthermore, this data collection process contributes to the national casuistry and is used as a sample for national surveillance.

- Another limitation may be the rate of under-reporting of percutaneous accidents (which is reported to be as high as $20 \%-30 \%$ ), which prevents us from estimating with confidence the real dimension of the problem.

\section{INTRODUCTION}

Percutaneous needlestick incidents (needlestick and sharps injuries (NSIs)) involving healthcare workers (HCWs) at risk for haemotransmitted infections (HIV, hepatitis $\mathrm{C}$ virus, hepatitis $\mathrm{B}$ virus) have been studied for some time; although surveillance systems and behavioural, procedural and prophylactic measures that have reduced the volume 
of accidents and seroconversions are now internationally implemented, the prevalence of percutaneous exposures should not be underestimated. ${ }^{1}$

Even before safety-engineered devices (SEDs) were disseminated, several studies issued a warning about the need to integrate the proven standard precautions with more effective preventative measures that prevent occupational exposure to the transmission of blood pathogens. ${ }^{2-4}$ It should also be noted that these precautions alone will never reduce the number of percutaneous accidents and possible exposures to transmitted agents to the greatest extent possible. ${ }^{56}$ In this framework, the use of safety devices, such as SEDs, seems to significantly reduce the frequency of percutaneous exposures.

Internationally, regulations have been issued to promote the dissemination of such devices, but to ensure that these devices are introduced effectively, staff must be trained in the use of the new tools. ${ }^{7}$ The devices should be more safe than the previous devices, and the devices should be introduced in a controlled and gradual manner to merge the improvements in safety with the available resources. $^{8}$

In USA, several studies have investigated NSIs after the introduction of SEDs. ${ }^{9}$ The number of accidents related to security devices increased at one point in time, but overall, the number of incidents decreased. A review ${ }^{10}$ analysed the studies conducted on the effectiveness of safety devices and reported that the number of incidents decreased by $22 \%-100 \%$; however, the authors of the review specified that there are many confounding factors in the data obtained. This aspect was confirmed by a Cochrane review, ${ }^{11}$ in which the results show that the studies examined had low quality and that there was large variability in the aspects analysed.

On the other hand, there are European studies that report positive results regarding the ability of SEDs to reduce the number of percutaneous accidents. ${ }^{12}$ Some authors reported a reduction in the number of exposures by $74 \%$ and identified the most important preventive factor in the use of SEDs. ${ }^{13}$ Similarly, in Great Britain, the use of SEDs was found to lead to a reduction in the total number of accidental punctures by $56 \%$ and $80 \%$, depending on the device analysed. ${ }^{14}$

In Italy, a recent study regarding the introduction of safety catheter devices in the Ligurian Regional Hospitals Network showed a correlation between this innovation and a decrease in the incidence rate of NSI among HCWs. ${ }^{15}$

Piedmont is a region situated in the northwest of Italy. Piedmont has more than 4375000 inhabitants, and the hospital service provided by the public health system is structured in 12 local health providers, named Azienda Sanitaria Locale; each of which manages from one to four acute care hospitals in the provincial territory of their own competence, three university hospital poles and other three public major hospitals. An epidemiological analysis of percutaneous biohazard incidents among HCWs in the Piedmont Regional Hospital Network has been reported in the past ${ }^{16}$ but more SEDs have been introduced in this area in recent years.

The aim of our study is to investigate the impact of the accidents related to the use of SEDs between hospital operators by analysing the data stored by the Studio Italiano Rischio Occupazionale da HIV ed altri patogeni emotrasmessi (SIROH) national surveillance and the Sorveglianza Incidenti Occupazionali Piemonte (SIOP) regional surveillance during the years 2014-2016 and examining the rates and dynamics of accidents involving SEDs in hospitals in the Piedmont.

\section{MATERIALS AND METHODS}

Data from the SIROH national surveillance system on occupational risk from sharps injuries and mucocutaneous exposure to HIV and other haemotransmitted pathogens were used, and the detailed information on occupational accidents was collected via standardised notification forms (derived from the Exposure Prevention Information Network (EPINET) system). The determinants of the incidents were investigated. Moreover, the regional surveillance system SIOP collected data on the structures, activities and resources of the hospitals participating in the surveillance (the number of employees, beds and days of hospitalisation including ordinary, dayhospital, day-surgery hospitalisation), device usage data for each hospital and analyses of the dynamics of percutaneous accidents occurring among HCWs.

With this information derived from the national and regional surveillance data, we conducted two analyses: for the 2014 data, we quantitatively compared the effectiveness of SEDs with that of conventional devices, and for the 2015-2016 data, we instead qualitatively analysed the dynamics of the registered NSIs.

Data processing was performed with the Stata V.14 statistical package. The data were stratified according to different variables to analyse the characteristics of the exposures.

For the quantitative analysis, the device usage data of the five devices most frequently involved in percutaneous accidents (butterfly needles, peripheral venous catheters, standard needles, vacutainer butterfly needles, vacutainer standard needles) with and without an SED were requested from the SIOP participating hospitals. On the basis of the incidents reported in 2014 from the SIROH database, we estimated the accident rates per 100000 needles used with $95 \%$ CIs for each device. We calculated the total accident rate for the safety and conventional devices, and to compare the efficacy of the safety devices with that of the conventional devices in preventing accidents, we estimated the relative risk (RR) with a $95 \%$ CI.

For the descriptive study, we identified from the SIROH system all the notification schedules of percutaneous accidents that occurred between January 2015 and December 2016 in our hospitals (1640 events); subsequently, we created an Excel database to correlate the injuries to the use of any safety or non-safety device and to examine the 
Table 1 Percentage distribution of device usage (conventional vs safety device) by type of device (2014)

\begin{tabular}{llllcr} 
& Butterfly & Peripheral & venous \\
needles & catheters & $\begin{array}{l}\text { Standard } \\
\text { needles }\end{array}$ & $\begin{array}{l}\text { Vacutainer } \\
\text { standard } \\
\text { needles }\end{array}$ & $\begin{array}{l}\text { Vacutainer } \\
\text { butterfly } \\
\text { needles }\end{array}$ \\
\hline Conventional device & $22.2 \%$ & $42.7 \%$ & $96 \%$ & $0.9 \%$ & $5.6 \%$ \\
Safety device & $77.8 \%$ & $57.3 \%$ & $4 \%$ & $99,1 \%$ & $94.4 \%$ \\
\hline
\end{tabular}

following characteristics: year of the accident, operators involved, site of the incident, device involved and its function, phase of the procedure in which it occurred and specifications, type of activation mechanism (active or passive activation mechanism of the SED), other factors concerning the dynamics, the training of the operator and the availability on site of sharps containers.

Forty-two health structures in Piedmont with a population of $37285 \mathrm{HCWs}$ (all the public acute care hospitals in our region except one that did not adhere to the regional surveillance procedures) were included because they reported percutaneous incidents occurring in the years considered and provided data on device usage and on the structural indicators of their hospital facilities.

\section{RESULTS}

\section{Quantitative analysis of sharps injuries}

The use of SEDs in the Piedmont region has expanded in recent years. In 2014, there were 1044 NSIs (with 209 SED-related accidents, $20 \%$ of the total NSIs) with an accident rate of 2.8 per $100 \mathrm{HCWs}$. A third of the injuries occurred with five types of devices: butterfly needles, standard needles (hypodermic needles), peripheral venous catheters, standard vacutainer needles and butterfly needles. Table 1 shows the percentage of device usage for the conventional version and the safety version of each of the five devices mentioned. The data show that standard needles have not been replaced by safety devices.

Regarding the replacement of conventional non-safety devices, we analysed the device-specific accident rates per 100000 needles used in 2014 to compare the safety version of the device to the conventional version. The results are summarised in figure 1, where a marked reduction in the injury rate with the safety version of butterfly and intravenous needles is observed. Table 2 shows the number of needles used (summed across the hospitals), the total number of accidents and the corresponding rates (per 100000 needles used). The accident rates related to the use of a device reduced for each type of needle considered, with a total accident rate of 1.07 for the SEDs and 1.32 for the non-safety devices.

We found an RR between the use of safety devices and the use of non-safety devices of 0.81 (95\% CI 0.64 to 1.03$)$. When the data on standard needles and related accidents were excluded, the use of safety needles significantly reduced the risk of a percutaneous accident with an RR of 0.28 (95\% CI 0.12 to 0.39 ). On the basis of only the standard needle data, the use of SEDs increases the risk of injury with an RR of 2.02 (95\% CI 1.19 to 3.43 ).

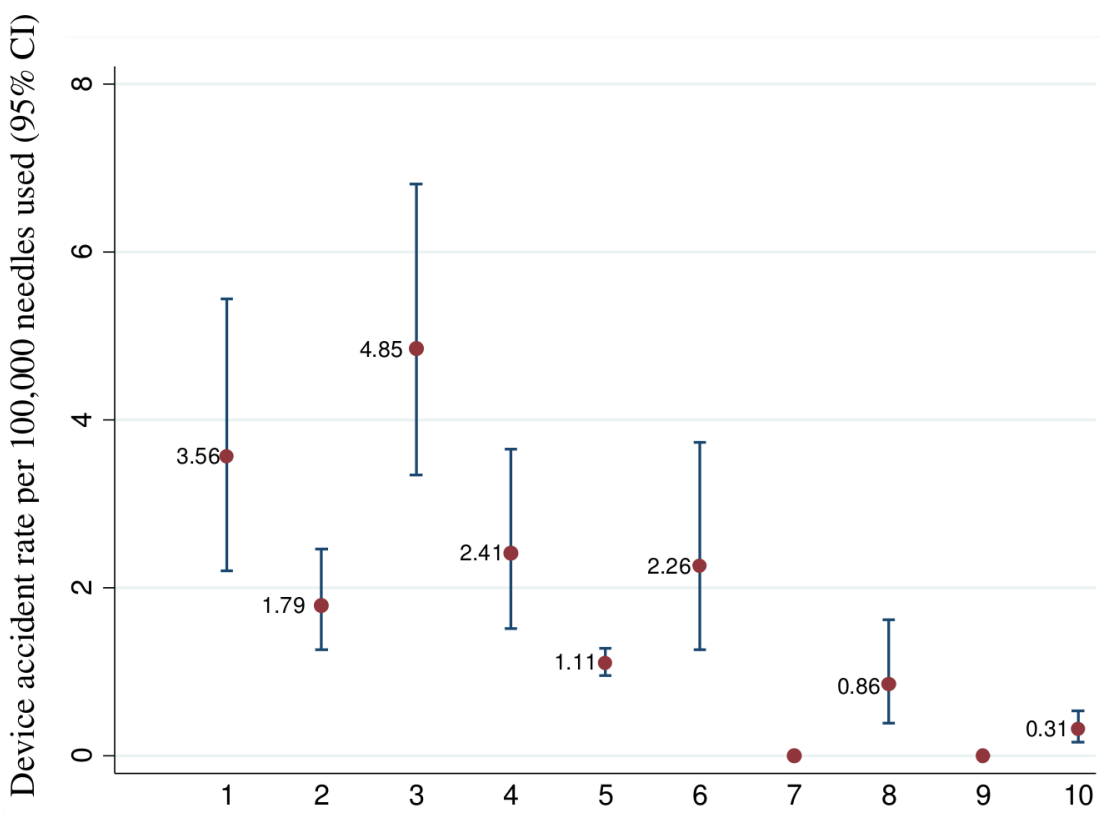

Figure legend:

1. Conventional butterfly needles

2. SED -Butterfly needles

3. Conventional peripheral venous catheter

4. SED - Peripheral venous catheter

5. Conventional standard needles

6. SED - Standard needles,

7. Conventional vacutainer standard needles

8. SED - Vacutainer standard needles

9. Conventional vacutainer butterfly needles

10. SED - Vacutainer butterfly needles

(Piedmont, 2014)

Figure 1 Specific device accident rate per 100000 needles with a 95\% Cl (conventional vs safety devices, considering five different devices, based on the 2014 consumption data). SEDs, safety-engineered devices. 
Table 2 Consumption of needles, number of related percutaneous accidents and accident rates/100 000 needles used (2014)

\section{Safety needles (total)}

\begin{tabular}{lll}
\hline No of consumed needles & 8893514 & 17306851 \\
\hline No of needles-related injury & 96 & 230 \\
\hline Accident rate/100 000 needles used & 1.07 & 1.32 \\
& $\begin{array}{l}\text { Safety needles } \\
\text { (excluding standard needles) }\end{array}$ & $\begin{array}{l}\text { Conventional needles (excluding standard } \\
\text { needles) }\end{array}$ \\
\hline No of consumed needles & 8229653 & 1528744 \\
\hline No of needles-related injury & 81 & 54 \\
\hline Accident rate/100 000 needles used & 0.98 & 3.53 \\
\hline No of consumed needles & Safety standard needles (only) & Conventional standard needles (only) \\
\hline No of needles-related injury & 663861 & 15778107 \\
\hline Accident rate/100 000 needles used & 2.25 & 176 \\
\hline
\end{tabular}

\section{Descriptive analysis on sharps injuries}

Between 2015 and 2016, the total number of accidents involving SEDs was 298 (167 in 2015, 131 in 2016) out of 1640 total accidents and decreased by $21 \%$ from 2015 to 2016. SEDs were related to accidents in $18 \%$ of the total number of percutaneous accidents.

Figure 2 shows the percentage of the sites where the accidents occurred, comparing the conventional devices and SEDs. The patient's room is the site at which the highest number of accidents occurred (152/298). Only $5 \%(15 / 298)$ of the accidents with SEDs occurred in the operating room, and considerably more accidents with conventional devices $(469 / 1342)$ occurred at this site.
The professional groups involved in the incidents analysed in the study are described in figure 3 . Nurses were involved in $50 \%(812 / 1640)$ of the NSIs in the 2-year period considered and were the professionals who were most exposed to SED-related incidents, as they were exposed to $78 \%$ of the total SED accidents recorded $(231 / 298)$. Surgeons were involved in $15 \%$ of the total NSIs $(247 / 1640)$, of which $97 \%$ were accidents related to non-safety devices. While the preponderance of nurses among healthcare professionals is clear, the ratio of NSIs with conventional devices compared with that of NSIs with SEDs was lower for nurses than for surgeons ( $70 \%$ vs $97 \%$ ). By analysing these two types of healthcare

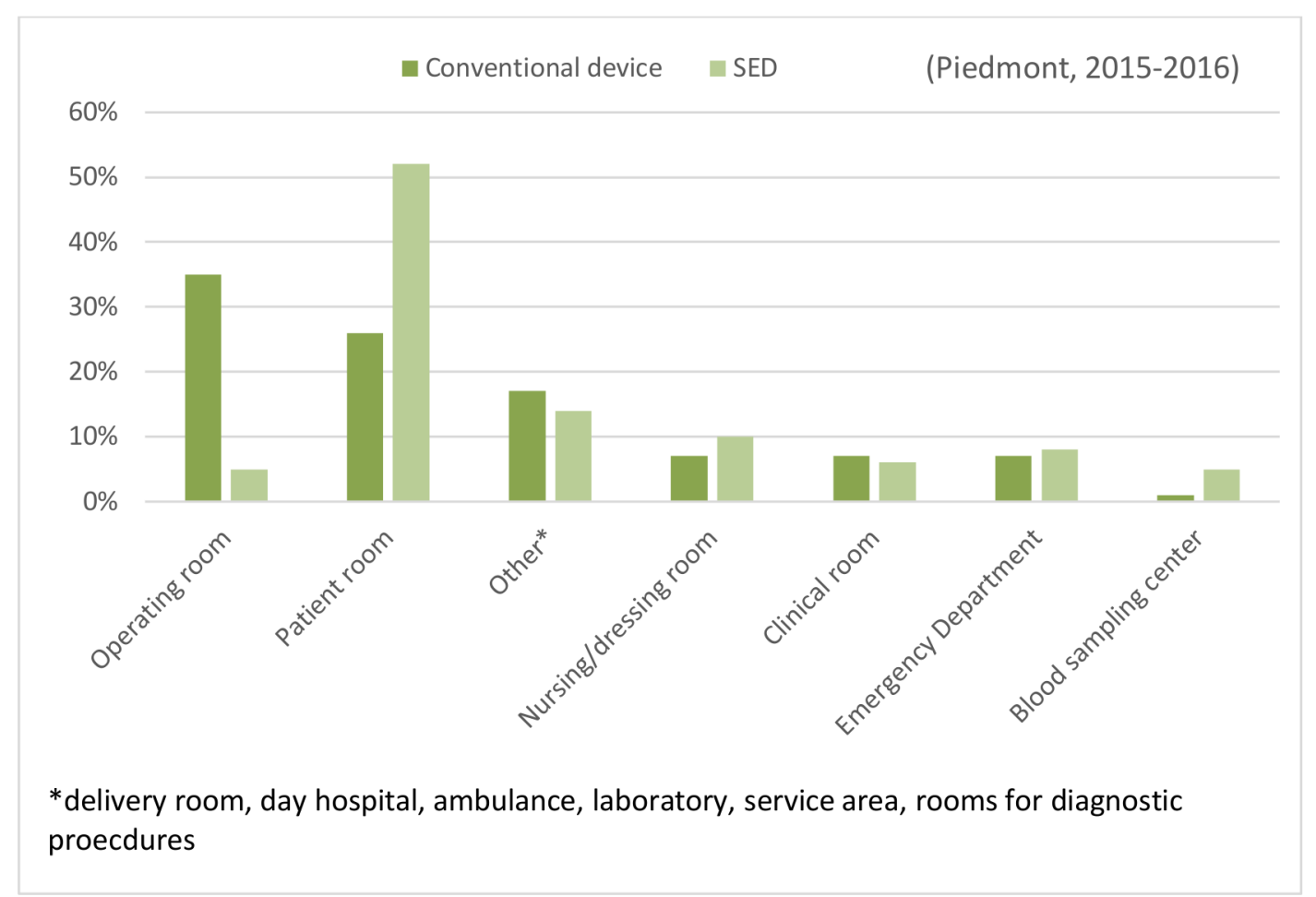

Figure 2 Place that has a major risk of percutaneous accidents. SED, safety-engineered device. 


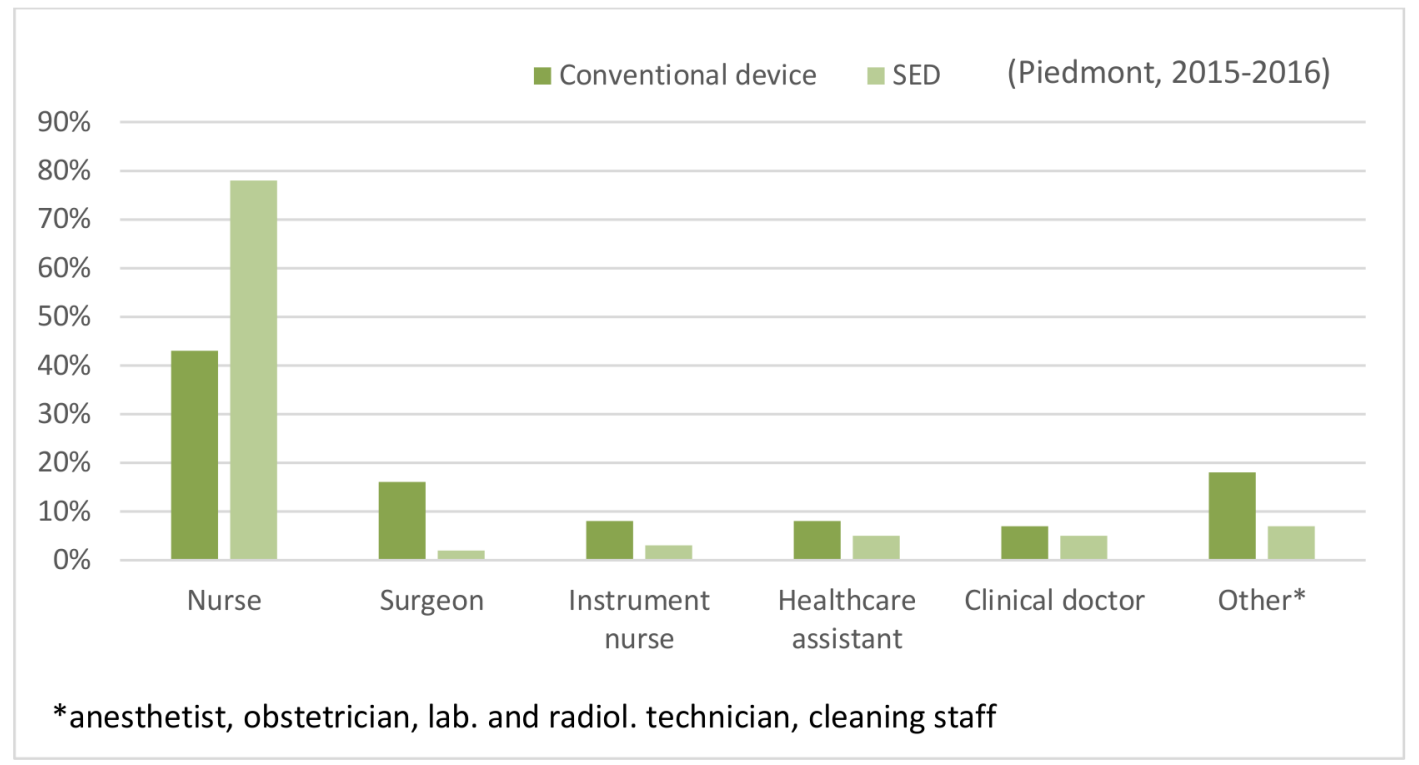

Figure 3 Professional groups with a major risk of percutaneous accidents. SED, safety-engineered device.

professionals as being represented in the healthcare staff with a proportion of 1:10 (surgeons to nurses), we observed that the accident rate for 100 users is 6.8 for surgeons and 2.2 for nurses.

Regarding SED-related injuries, the most frequent security devices involved were butterfly needles $(26 \%$, with $77 / 298$ percutaneous exposures), peripheral venous catheters (42/298) and insulin and tuberculin syringes (29/298); the most involved procedures were venous sampling, which was involved in $40 \%(119 / 298)$ of the injuries, phlebotherapy and the search for vascular access, which were involved in $16 \%(48 / 298)$ of the injuries, and subcutaneous/intramuscular injections, which were involved in 13\% (39/298) of the injuries.

The comparison with the conventional controls shows considerable differences: the most frequent accidents were those related to the use of suture needles $(244 / 1342$, $18 \%)$ and disposable syringes (standard) (192/1342, $10 \%)$; suturing (18\%) and the administration of injections $(15 \%)$ were the procedures with the highest risks.

Regarding the dynamics of the injuries, we found that, as expected, most of the accidents occurred during the use of the device (due to the distraction of the operator, unexpected movements of the patient, or the complexity of a multistep procedure), both with conventional devices $(50 \%)$ and with SEDs (47\%). Unexpectedly, in the phases 'after use but before final elimination' and 'elimination in the appropriate container', conventional safeguards were involved in $24 \%$ and $8 \%$ of the cases, respectively, and SEDs were involved in $32 \%$ and $13 \%$ of the cases, respectively.

The major specifications of exposure with the conventional devices concerning the elimination phases that highlight malpractice were: $6 \%$ of percutaneous events occurred because the user tried to 'dismantle a device in its parts $; 5 \%$ of the injuries from an object left close to the disposal container', $1 \%$ of accidents because of the 're-capping of a used needle'.

The vast majority of accidents occurred with SEDs that require manual activation of the safety mechanism $(92 \%$ of cases). Devices with passive activation modalities were related only to $7 \%$ of the accidents. In particular, devices with the manually activated sliding shield were involved in $74 \%$ of the injuries, those with semiautomatic activation mechanism were involved in $11 \%$ of the injuries and those with manually activated protective shielding were involved in $4 \%$ of the injuries. We also analysed whether the security system was active in the injury, and we observed that in $81 \%$ of cases, there was a failure to activate the security mechanism, while a regular activation occurred in only in 15\% of the accidents.

Figure 4 shows an in-depth analysis of the phases during which the accident occurred, focusing on how the security system failed. The expression 'for failure to activate the safety device' describes malfunctions such as failure to activate, breakage, partial activation or incomplete activation. A significant proportion of the accidents occurred at the end of the procedure, which is when the SED should have prevented the accident.

Regarding the training of HCWs regarding the correct use of safety devices, specific training was present in $93 \%$ of the cases, while a lack of training was reported only in $3 \%$ of the accidents. In the remaining $4 \%$ of the accidents, it did not apply because the subject was not the user of the device.

\section{DISCUSSION}

The introduction of safety devices known as SEDs into hospital practice has been regulated in the USA by the new requirements of the Needlestick Safety and Prevention Act of the United States Occupational Safety and 


\section{Before the procedure, and before activation of the safety device \\ During the procedure, when the activation of the safety device was not yet possible \\ The procedure ended but before the activation of the safety device was possible \\ For failure to activate the safety device \\ Once the procedure has been completed, during the activation of the safety device \\ After activation of the safety device Missing data \\ (Piedmont, 2015-2016)

Figure 4 Phases in which the safety mechanism of security devices has failed.

Health Administration. ${ }^{17}$ The European Community subsequently disclosed the European Directive 2010/32/ EU, ${ }^{18}$ and Italy consequently disclosed the Legislative Decree $19 / 2014^{19}$ that incorporates European regulations, allowing the use of 'medical devices equipped with protection mechanisms and security' and surveillance on these issues. $^{20}$

The use of SEDs in the Piedmont region has expanded in recent years. In the 3-year period considered, from 2014 to 2016, there was a reduction in the absolute number of accidents despite an ever-increasing number of uses of SEDs. A reduction in the number of accidents involving safety devices has also been observed; this reduction could be attributed to an improvement in the SED design, a better training procedure for the operators to use the devices correctly, and to a greater familiarity with this kind of instrument.

Even though the use of safety devices seems to result in a reduction in accident risk, it must be considered that in calculating the accident rates for 100000 devices used, the total number of used devices includes that of standard needles. Standard needle is not frequently used in procedures on the patient and therefore hypothetically poses zero risk. According to unpublished data, only $30 \%$ of standard needles are used on the patients; $70 \%$ of standard needles are used for different purposes (such as drug dilution); in addition, the amount of consumption of standard needles is $90 \%$ of the total consumption of conventional needles. These biases could explain why, from our data, the preventative effectiveness of all SEDs compared with that of conventional devices does not demonstrate statistical significance.

However, the decrease in the accident rates by more than half in 100000 needles used with the use of SEDs suggests the importance of introducing SEDs for accident prevention. Various authors and the authors of a recent review of the factors that promote safety regarding NSIs among HCWs show the most favourable results for the adoption of safety devices in routine clinical practice and suggest that this policy should be considered a part of any sharps injury prevention programme..$^{21-23}$

Conventional non-safety devices continue to cause most of the percutaneous injuries; in our study, they were responsible for $82 \%$ of the total accidents. Despite the introduction of SEDs, some categories of standard devices remain the most used devices in some procedures, as for some procedures, there is not a safety device of equivalent efficacy; for example, there is not a safety device of equivalent efficacy for suturing needles, and they are among the most frequently used conventional devices implicated in sharps injuries (18\%). Our findings are confirmed by those of other studies ${ }^{24}$ and highlight the importance of the operating room as an accident site; the number of accidents at this site has been increasing relative to those at other sites, and our findings suggest that even in situations in which the use of SEDs has been increasing, implementing safety procedures at that location is difficult.

On the basis of the analysis of the accidents related to safety devices, the patient's room was the location at which the most accidents occurred, and nurses were the HCWs who had the highest proportion of exposure to these accidents, most likely because procedures involving nurses at the patient's bed are frequent and are the procedures that most frequently involve the use of SEDs. Therefore, these aspects comprise one of the areas that must be targeted by interventions for sharps incident prevention, as proposed by an overview based on EPINET UK data. ${ }^{25}$

The safety devices most often involved in the accidents were butterfly needles and cannula needles, which are widely used devices that have almost completely replaced 
the equivalent conventional devices. The high number of injuries occurring with these tools was shown to be related to the widespread use of these devices in the current clinical practice, ${ }^{21}$ the easy recognition of the needle involved, or the greater propensity of the operator to report percutaneous accidents occurring with needles intensively contaminated by blood. However, our results regarding the device-specific accident rates confirm the results that other authors have reported; the highest efficacy was measured for the safety devices introduced for intravenous catheterisation and blood sampling. ${ }^{26-28}$

Descriptive analysis of the incidents was particularly useful for understanding the dynamics of the accidents. With both standard (50\%) and safety $(47 \%)$ devices, most of the accidents occurred when the device was used on the patient, and the accidents were only partially preventable with appropriate behavioural and standard protective measures.

Since SEDs are devices that should avoid exposure to the end of the procedure, we expected an increase in the relative frequency of injuries during the use of the device, with a decrease in the number of accidents occurring after the procedure was completed; however, this situation did not occur. The use of SEDs decreased the proportion of NSIs during the procedures, and therefore, the proportion of NSIs occurring after the procedures will increase by necessity.

An interesting study on the efficacy of SEDs ${ }^{26}$ describes considerable reductions in percutaneous injury rates achieved across all categories regarding the timing of injury (during/after the procedure and during the disposal). In our results, approximately $20 \%$ of the exposures occurred during the activation of the security mechanism, but the mechanism responsible for the few incidents with SEDs described involved manual activation and either problems in staff training or deficiencies in the safety mechanism.

Similar results were found by other authors that explained how the differences in the safety activation mechanism (between 'passive', 'semiactive' and 'active') are fundamental in the prevention of this kind of accident. ${ }^{12}{ }^{28}$ Furthermore, it is also important to consider that the introduction of new safety devices requires an adaptation time that can reduce the expected impact in the short term and that a tool shows the highest level of efficacy when it is introduced gradually. ${ }^{29}$

The literature also highlights the problem of underreporting NSIs, as the number of accidents at risk of biological transmission for HCWs has been shown to be 2 -fold ${ }^{30}$ to 10 -fold larger than that reported. ${ }^{21}$ We were not able to calculate the under-reporting rate in our study, but from the data collected in the field and unpublished data, our under-reporting rate is estimated to be approximately $20 \%-30 \%$.

\section{CONCLUSIONS}

From 2014 to 2016, the absolute number of percutaneous accidents involving HCWs in hospitals in Piedmont decreased; an evident reduction was expected to occur after the introduction of the security devices, but the data were collected over a period of insufficient length to highlight major changes. After the introduction of the SED regulations, accident rates for some devices decreased (even by $50 \%$ ), and the use of safety devices seems to reduce the risk of percutaneous accidents, but the findings regarding the accident dynamics are not completely convincing.

Currently, at least in the Piedmont region, the introduction of SEDs in daily practice occurred relatively recently, and most of the SEDs introduced since 2016 had a manual mechanism of activation. We expect continuous improvement in the accident rates with the gradual elimination of conventional devices (and the introduction of more passive activation security devices) and an increasing familiarity in use of these tools among operators.

Device-specific injury rates provide the most direct comparisons of safety performance, ${ }^{31}$ but because a substantial number of accidents continue to occur, there is a need for improvements in the training process of employees, for the monitoring of welfare practices, and for a deeper search for technological solutions that are easy to use, effective and safe. To realise an improvement in the control of HCWs' occupational condition and risks, ${ }^{24} 32$ an involvement in hospital management is also important to provide adequate training to hospital staff, to promote HCWs' awareness of NSIs and to prevent difficult working conditions.

The increase in the use of automatic safety devices, combined with proper training programmes and the involvement of hospital management and HCWs in the selection of safety devices, can lead to a reduction in the remaining incidence of percutaneous injuries.

Acknowledgements This study used data from the SIOP-SIROH surveillance, which was conducted as part of a regional programme for the prevention of infections, received assistance from the working group coordinated by the Public Health Management established in 2012 and was carried out with the support of the SIROH project, which was coordinated by 'Istituto Nazionale per le Malattie Infettive Lazzaro Spallanzani-Rome'. The regional working group (GLICA) is headed by Hospital Care Quality Management (Det. 286; 3/5/2017) and includes the following individuals: P.A. Argentero, S. Bagnato, A. Biglino, F.G. De Rosa, V. Ghisetti, A. Macor, S. Livigni, R. Raso, A. Rocchetti, L. Scaglione, C. Silvestre and C.M. Zotti.

Collaborators The following hospitals participate in the SIOP project of the Piedmont region: AOU Città della Salute e della Scienza di Torino: M. Coggiola, N. Cotto, A. Spigo, L. Forno, C. Silvestre, F. Gremo, G. Guareschi; A0U Maggiore della Carità di Novara: M. Tacchini; AO SS: Antonio, Biagio e C. Arrigo di Alessandria: C. Penna, M. Bergaglia; AO S. Croce e Carle di Cuneo: P. Pellegrino, P. Occelli; A0 Ordine Mauriziano: I. Vigna; ASL Città di Torino: B. Delfino, V. Cascio, L. Maurto, M. Aime, T. Emanuele, G. Calautti; ASL T03: P.A. Argentero, M. Campobasso, A. Gallone, B. Viviani; ASL T04: L. Marco, R. Cavallo; ASL T05: D. Morabito; ASL Vercelli: S. Gatti, G. Patriarca; ASL Biella: F. D’Aloia, M. Ruggeri, C. Piva; ASL Novara: D. Kozel; ASL VCO e COQ: M. Bignamini, T. Romani; ASL CN1: M. Salvatico, A. Rapa; ASL CN2: dott.sa V. Venturino, M. Rabino; ASL AL: A. Minoglio, A. Galiano; and ASL AT: L. Gandini, G. Gai, R. Broda.

Contributors Design of the work: CMZ, PAA, AA and MCO. Acquisition, analysis and interpretation of the data: CMZ, AA, PAA and MCO. Direct or indirect participation in drafting the work: all authors. Critical revision: CMZ, PAA, GG and MCO. Each author 
agrees to be accountable for all aspects of the work and confirms that questions related to the accuracy or integrity of any part of the work will be appropriately investigated and resolved.

Funding The authors have not declared a specific grant for this research from any funding agency in the public, commercial or not-for-profit sectors.

Competing interests None declared.

Patient consent for publication Not required.

Provenance and peer review Not commissioned; externally peer reviewed.

Data availability statement Data may be obtained from a third party and are not publicly available.

Open access This is an open access article distributed in accordance with the Creative Commons Attribution Non Commercial (CC BY-NC 4.0) license, which permits others to distribute, remix, adapt, build upon this work non-commercially, and license their derivative works on different terms, provided the original work is properly cited, appropriate credit is given, any changes made indicated, and the use is non-commercial. See: http://creativecommons.org/licenses/by-nc/4.0/.

\section{ORCID iD}

Maria Chiara Ottino http://orcid.org/0000-0002-4573-0774

\section{REFERENCES}

1 Saia M. Friedrich Hofmann,Joanna Sharman,Dominique Abiteboul,Magda Campins,Joerg Burkowitz,Yoonhee Choe SK. Needlestick Injuries: Incidence and Cost in the United States, United Kingdom, Germany, France, Italy, and Spain. Biomed Int 2010;1:44-9.

2 Ippolito G, Puro V, De CG. The risk of occupational human immunodeficiency virus infection in health care workers. Arch Intern Med 1993;153:1451-8.

3 Kelen GD, Green GB, Hexter DA. Substantial improvement in compliance with universal precautions in an emergency department following institution of policy. Arch Intern Med 1991;151:2051-6.

4 Nelsing S, Nielsen TL, Nielsen JO. Occupational blood exposure among health care workers: II. exposure mechanisms and universal precautions. Scand J Infect Dis 1993;25:199-205.

5 Jagger J, Pearson RD. Universal precautions: still missing the point on Needlesticks. Infection Control and Hospital Epidemiology 1991;12:211-3.

6 Tokars Jlet al. Percutaneous injuries during surgical procedures. JAMA 1992;267:2899-904.

7 Aziz A-M. Do training and needle-safety devices prevent needlestick injuries? A systematised review of the literature. Br J Nurs 2018;27:944-52

8 Direzione Generale Sanit e Politiche Sociali RER. Linee di indirizzo e criteri d'uso dei dispositivi medici con meccanismo di sicurezza per la prevenzione di ferite da taglio o da punta 2015.

9 Phillips EK, Conaway MR, Jagger JC. Percutaneous injuries before and after the needlestick safety and prevention act. $N$ Engl $J$ Med 2012;366:670-1.

10 Tuma S, Sepkowitz KA. Efficacy of safety-engineered device implementation in the prevention of percutaneous injuries: a review of published studies. Clin Infect Dis 2006;42:1159-70.

11 Lavoie M-C, Verbeek JH, Pahwa M, et al. Devices for preventing percutaneous exposure injuries caused by needles in healthcare personnel. Cochrane Database Syst Rev 2014;54.

12 Tosini W, Ciotti C, Goyer F, et al. Needlestick injury rates according to different types of safety-engineered devices: results of a French multicenter study. Infect Control Hosp Epidemiol 2010;31:402-7.

13 Lamontagne F, Abiteboul D, Lolom I, et al. Role of safety-engineered devices in preventing needlestick injuries in 32 French hospitals. Infect Control Hosp Epidemiol 2007;28:18-23.

14 Cullen BL, Genasi F, Symington I, et al. Potential for reported needlestick injury prevention among healthcare workers through safety device usage and improvement of guideline adherence: expert panel assessment. J Hosp Infect 2006;63:445-51.

15 Sossai D, Guardo MDI, Foscoli R, et al. Efficacy of safety catheter devices in the prevention of occupational needlestick injuries : applied research in the Liguria Region (Italy). J PrevMed Hyg 2016;57:110-4.

16 Argentero PA, Zotti CM, De Carli G, et al. Sorveglianza regionale delle esposizioni professionali percutanee o mucocutanee a patogeni a trasmissione ematica negli operatori sanitari : aree di intervento preventivo. Med Lav 2007:98:145-55.

17 United States Departement of Labor. Bloodborne pathogens. - 1910.1030 | Occupational Safety and Health Administration. Available: www.osha.gov/pls/oshaweb/owadisp.show_document?p $\mathrm{id}=10051 \& p \_$table $=$STANDARDS

18 EU-OSHA. Directive 2010/32/EU - prevention from sharp injuries in the hospital and healthcare sector - Sicurezza e salute sul lavoro - EU-OSHA, 2010. Available: https://osha.europa.eu/it/legislation/ directives/council-directive-2010-32-eu-prevention-from-sharpinjuries-in-the-hospital-and-healthcare-sector

19 Gazzetta Ufficiale DELLA Repubblica italiana. Decreto Legislativo 19/2014, N. 19, 2015. Available: http://www.gazzettaufficiale.it/eli/id/ 2014/03/10/14G00031/sg

20 Gruppo di studio P. Prevenzione dell'esposizione occupazionale al rischio biologico derivante da lesione percutanea accidentale (puntura, ferita, taglio) nel settore ospedaliero e sanitario Compendio tecnico e raccomandazioni per il recepimento e l'attuazione in Italia della Direttiva 2010/32/UE del Consiglio dell'Unione Europea, 2012. Available: https://medicocompetente.it/files/documenti/622-Laprevenzione-delle-punture-accidentali.pdf

21 Elder A, Paterson C. Sharps injuries in UK health care: a review of injury rates, viral transmission and potential efficacy of safety devices. Occup Med 2006.

22 Wicker S, Jung J, Allwinn R, et al. Prevalence and prevention of needlestick injuries among health care workers in a German university hospital. Int Arch Occup Environ Health 2008;81:347-54.

23 Ballout RA, Diab B, Harb AC, et al. Use of safety-engineered devices by healthcare workers for intravenous and/or phlebotomy procedures in healthcare settings: a systematic review and meta-analysis. BMC Health Serv Res 2016;16:458.

24 Vaughn TE, McCoy KD, Beekmann SE, et al. Factors promoting consistent adherence to safe needle precautions among hospital workers. Infect. Control Hosp. Epidemiol. 2004;25:548-55.

25 Sohn S, Eagan J, Sepkowitz KA, et al. Effect of implementing SafetyEngineered devices on percutaneous injury epidemiology. Infect. Control Hosp. Epidemiol. 2004;25:536-42.

26 Rogues A-M, Verdun-Esquer C, Buisson-Valles I, et al. Impact of safety devices for preventing percutaneous injuries related to phlebotomy procedures in health care workers. Am J Infect Control 2004;32:441-4

27 Mendelson MH, Lin-Chen BY, Solomon R, et al. Evaluation of a safety resheathable winged steel needle for prevention of percutaneous injuries associated with intravascular-access procedures among healthcare workers. Infect Control Hosp Epidemiol 2003;24:105-12.

28 Jagger J, Berguer R, Phillips EK, et al. Increase in sharps injuries in surgical settings versus nonsurgical settings after passage of national needlestick legislation.'reproduced with permission from the Journal of the American College of Surgeons. Aorn J 2011;93:322-30.

29 Frickmann $\mathrm{H}$, Schmeja W, Reisinger E, et al. Risk reduction of needle stick injuries due to continuous shift from unsafe to safe instruments at a German university hospital. Eur J Microbiol Immunol 2016;6:227-37.

30 CDC. Overview: risks and prevention of sharp injuries in healthcare personnel. Atlanta GA: CDC, 2004.

31 Jagger J, Perry J. Safety-engineered devices in 2012: the critical role of healthcare workers in device selection. Infect Control Hosp Epidemiol 2013;34:615-8.

32 Wicker S, Dienst B, Ludwig A-M, et al. Wiener klinische Wochenschrift Nadelstichverletzungen bei Mitarbeitern Im Gesundheitswesen: Berufsrisiko Oder vermeidbare Gefährdung? needlestick injuries among health care workers: occupational hazard or avoidable hazard? Wien Klin Wochenschr 2008;120:486-92. 